\title{
Physicalism, Behaviorism and Incompleteness
}

\author{
Tao Li \\ Department of Social Science, Air Force College in Xuzhou \\ Xuzhou 221000, China \\ Tel: 86-516-8772-2605 E-mail: jlsr1230@163.com
}

Received: December 20, 2010 Accepted: January 14, 2011 doi:10.5539/ass.v7n5p203

\begin{abstract}
The content of this paper contains four parts. (1) First, physicalism gives the enlightenments to behaviorism: mind-body identity, objectivity like physics and completeness of reduction. (2) Secondly, there are difficulties which behaviorist could not overcome - both the reduction of the theory and the terms are unreliable, and the strict distinction between introspective method and inter-subjective method is also untenable. (3) Thirdly, It has inevitable incompleteness in one theory no matter what it claims due to the limitations of human cognition. (4) Finally, the author concludes that we should treat various theories in a "both this and that" but "either this or that" way. Therefore, we should admit the contribution of behaviorism and its model philosophy - physicalism, although they has failed in seeking for completeness.
\end{abstract}

Keywords: Physicalism, Behaviorism, Incompleteness, Scientific philosophy

\section{Enlightenments to behaviorism from physicalism}

It is just as Carnap admitted that the two currents of physicalism and behaviorism tended towards the same direction. (Hung, 1984) Corresponding to the attempt to expel the traditional speculation from philosophy, behaviorism as a revolution, intended to make psychology scientific via physics which was esteemed as a model of sciences. Physicalist had a profound influence upon behaviorists who were to seek universal laws by means of experimental methods like physics.

\subsection{Mind-body identity}

First of all, we may say that the faith of mind-body identity helped behaviorists to find a breakthrough point to cope with mental problems. According to physicalist reductionism, the relation between mental state and physical state is identical, not only in quantity but also in reference. To speak in mental or in physical terms is just to adopt one or other way of describing the same object. (Ayer, 1994) All actual things are natural, and metal life is within nature as a whole, but as an opposite of nature. In H. Feigl's view, mental occurrences are identified with processes in the physiological system. The only way to have access to the complete knowledge of mind must depends on employing concepts of the quantity of natural science to refer mental qualities; so you may change psycho-physical connection into identical connection, which is single, and avoid making things complicated.

\subsection{Objectivity like physics}

Just in conformity with physicalist two principles-all scientific statements are inter-subjectively testable and there is an unified explanatory system deduced from physical theories-behaviorists differs from other psychological paradigms. Behaviorism requires that research procedure should be objective, credible and be testable. Carnap once approached this subject and provided some opinions shown in Skinner's thought later. (Feigl, 1963)

Behaviorist psychology attempted to give a state of natural science to psychology and attributed the whole subject of human behavior to stimulus-response. Thus, psychology may gain testability and been treated as an experimental science about objective behavior other than trying to find what happened within mind by the subjective ways.

The Physicalist stressed that physical language is objective and inter-subjective, and paid attention to operation of scientific observation. By means of precise science, behaviorists wanted to get rid of all dualism and claimed 
that physics was the most definite knowledge in all human knowledge. They believed that psychological laws were special cases in physical laws, and psychological terms could be translated into physical language too.

\subsection{Completeness of reduction}

The behaviorist agreed with physicalist standpoint, arguing that their reduction of human mind was surely complete. It was only by sentences relevant to physical action, behavior and speech; we could describe human psychology such as feelings. As empirical fact, physical language did seem to be enough to give a complete description of the world.

Skinner carried on removing consciousness from psychology. (Skinner, 1982) He maintained that both the sensation and thinking, as occurrences within an organism, were just forms of action which was a kind of response process of private stimulus. And such inner process abided by the external relations of stimulus-response; and could be also interpreted by scientific analysis of empirical facts. Therefore, there was no need to approach private events through direct experience, but through behavior.

Behaviorist psychology held that the variables in casual connection between behavior and environment could provide experimental analysis of systems directly; and it was unnecessary to use any intervening explanation. Accordingly, what Skinner said means that behaviorist psychology is complete, and why consciousness psychology still exists is due to the underdevelopment of other psychologist schools.

Is this assessment of Skinner tenable?

\section{Difficulties of behaviorism}

\subsection{Reduction of the theory}

The first consideration is about the theoretical reduction. The studies of Watson and Skinner were both based on animal physiology. Watson dealt with human emotions as endocrine phenomena, thinking as noiseless speech which was only the motion of vocal cords. These assumptions which reduced human mind into the physical state have received many refutations. (Wartofsky, 2009) In fact, the behavioral reduction, in which behaviorists have neglected the special object of psychology - human mind - is a unified whole; is an immature, quantitative expression which is completely founded on the observation of partial phenomena.

\subsection{Reduction of terms}

It has also been reproached that the reduction of terms in behaviorism. Chomsky pointed out that Skinner's basic terms, such as "stimulus, response, reinforcement", could not be expanded into human behavior without a great revision, for this was an excessive magnification of such technical terms. And the definition of "stimulus" would be indistinct, if it were apart from a certain laboratory context.

Bridgeman also showed that there were different levels in various languages, and most chaos in the interpretations of modern physics was caused by wrong way, in which new developments were forced into the fashionable language mode at present. But two kinds of languages should be available at different levels; they could not be completely translated into each other although they might be related mutually. Furthermore, physical language is not absolutely inter-subjective, for it can not be separated totally from our ordinary language. On the other hand, what physical language describes are observable objects, not abstract sensory data; this brings about the inter-subjectivity qualified.

\subsection{Distinction between introspective and inter-subjective methods}

In my part, the distinction between introspective and inter-subjective methods is also partial, for there is not a clear boundary between the two kinds of approaches. It is impossible that the studies of psychology keep themselves apart from subject, even if physics, called as objective knowledge now, is also can not be divorced from the observers at all. Watson expelled the introspective method out of the front door, and then employed it back in the form of language reports from the back door. In reality, through the technical advances some introspective data might change into objective data to a certain extent. And it is a blurred demand in itself that can be inter-subjectively verified or refuted in principle.

In fact, behaviorism combined psychology with natural science with the help of some doctrines as follows: Physical monism (or Reductionism), Mechanism, Operationism and Determinationism. Just based on these assumptions, behaviorist differs from other psychological school, such as psychoanalytic and humanistic psychology. Behaviorism may avail itself of present conditions which we have reached to approach, to some extent, inter-subjective human behavior; but it is a wrong conclusion which claims that the behaviorist research is complete and there is no need for the introspective method in psychological researches. 


\section{Inevitable incompleteness}

\subsection{Just one point of view}

I believe that all researching methods or theories are limited according to the assumptions from the beginning. Behaviorism could provide at best an incomplete description of human being and at worst a wholly false one. A man is not a machine or an "empty organism", can not be objectivitized, quantitative, and reduced to a unit of "stimulus-response".

Apart from the behaviorist, psychoanalyst and humanistic school are the other dominating schools in psychology. What are the distinctions among the three explanations? Freud would seek reasons from inner conflicts, Skinner form overt connections of behavior, and Rogers from internal tendencies. (Rogers, 1980) Is not any of the three reasonable? Each paradigm differs from others simply in its methodology with relevant standards of values. And each selected approach has shown fractional truth, even though they are incompatible.

It is obvious that behaviorism is not superior to other theories, in spite of its efforts at pursing objectivity and inter-subjectivity of that kind of physics. Behaviorists have gong beyond the scope of this methodological framework, when giving the definition of psychology in kind of exclusive way; and can not settle the mind-body problem just by getting rid of mind in their studies. (Hellman, 1988) It is evident according to the foregoing discussion that whether a research paradigm includes mind or not has nothing to do with a closer description of the real world; it is just a problem of the angle of view, which leads to different horizons. Every paradigm has its relevant background which consists of theoretical assumptions and other boundary conditions; based on certain characteristic ideas the point of view has been involved in the construction of the theory.

\subsection{No perfect theory}

Why couldn't we reach the completeness just in one perfect theory, which is the aim of many scientists all the time? In psychology, for example, skinner claimed that behaviorist paradigm was both reliable and complete. But I shall show next that in one scientific theory the two demands are incompatible with each other. Firstly, Gödel even demonstrated at least that no proof of the consistency of any deductive system, which is rich enough, could be represented within the system, i.e. this system could not be both compatible and complete. Secondly, Popper also pointed out that the richer a theory got, the less its probability of verification was.

It means that in a theory the excessive demand for either of abundance or verifiability will lead to the loss of the other, for the relation of the two is inversely proportional. (Popper, 1992) The researches of Gödel and Popper have suggested a shatter of a human ideal which believes that we can get both reliability and completeness within a certain perfectible theory.

\subsection{Limitations of human cognition}

This kind of incompatibility, I believe, is closely related with the diversity of horizons which indicate the restrictions on human cognitive ability. These restrictions come from; on the other hand, the world of reality is carried and complicated, even in conflict, from the limitations of our physiology and psychology, such as the ability of memory, imagination and dealing with the message. We have to admit that we have many limitations of our language and logic.

Human being is often placed in a dilemma, facing a difficult choice. For instance, in astronomy surveying, when you need a precise detail, you would reduce the visual field giving up a research of large scale at the same time. In this case, the synthesis of research of two scales maybe can come true later on, but can not in other circumstances. In psychology, it is difficult to combine different paradigms base upon even incompatible assumptions into one, although they are not absolutely incommensurable. (Boris, 1993)

\section{Conclusion}

Following the previous discussion which has indicated the variety of human horizons and the incompatibility of reliability and completeness, I should admit that it is inevitable that there is incompleteness in every constructed scientific theory, for it must have made some definite conventions via its prerequisite assumptions to achieve the reliability of the theory itself.

Yet I want to make one more point that it is not necessarily true that the treatment of various theories in a "both this and that" but "either this or that" way would bring about a passive skepticism and an extreme relativism. On the contrary, what I mean is just owing to the limitations of human understanding, it is reasonable that there are such incomplete theories. We have to make certain definite choices from the multi-dimensional reasonable reality in order to avoid staying at the level of the indistinct, global generality for ever. Based on the exclusive options, scientists can construct ideal theories, which promote our understanding of real world, although they 
have to miss some factors usually. A belief would become powerful in a framework of the assumption. The idealization helps us free from the impossible task to describe the whole reality by some neglect. And the ideal theory make mankind has a possibility to advance interpretations on observational phenomena. Only on the assumption are the prerequisites correct.

According to the foregoing viewpoint, we should admit the contribution of behaviorism and its model philosophy of physicalism which was proposed by Viennese circle in order to change philosophy with scientific method, logical techniques and insistence on clarity. For my part, we ought to distinguish between the degree of a theory's access to so-called truth and its effects on human understanding progress in history. If we did not take behaviorism as an extreme stance, but think it made human knowledge accumulative by degrees, we may admit behaviorism, as the physicalist did, is a great progress of human cognition which is limited for good.

\section{References}

Ayer, A. J. (1994). Philosophy in the twentieth century. London: Unwin Paperbacks, pp. 112.

Boris, D. (1993). The paradigm in open philosophy. Super philosophy, 2, 27.

Feigl, H. (1963). Physicalism, unity of science and the foundations of psychology. In Hung, Tscha. Logical empiricism. Beijing: The Commercial Press, pp. 515.

Hellman, G. (1988). New trend in philosophy of science. Studies in dialectic of nature, 6, 19-22.

Hung, Tscha. (1984). Logical empiricism. Beijing: The Commercial Press, pp. 493.

Popper, K. R. (1992). Conjectures and refutations. London: Routledge, pp. 229

Rogers, C. R. (1980). Some issues concerning the control of human behavior. Boston: Houghton Mifflin, pp. 1064.

Skinner, B. F. (1982). An experimental analysis of operational behavior. New York: Prentice-Hall, pp. 302.

Wartofsky, M. W. (2009). Conceptual foundations of scientific thought-An introduction to the philosophy of science. Londong: Collier-Macmillan, pp. 347. 